\title{
Analysis of Electrical stresses in AC Switches Used for Control of Small Power Motors Present in Household Appliances
}

\author{
Yves Raingeaud, Franck Galtie, Laurent Gonthier and Jean Baillou
}

University of Tours, LMP- Power Microelectronics Laboratory 16 Rue Pierre and Marie Curie, BP7155, 37071 Tours Cedex 2, France, Tel: 02474240 00, Fax: 02475101 34.Email: raingeaud@univ-tours.fr,franck.galtie@st.com, laurent.gonthier@st.com,baillou@univ-tours.fr.

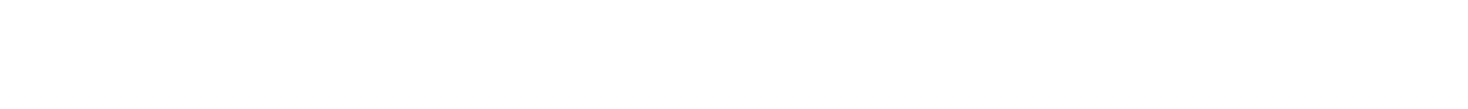

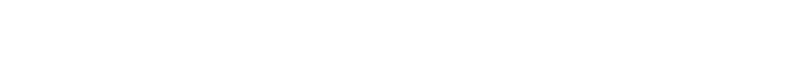

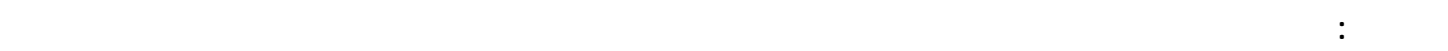

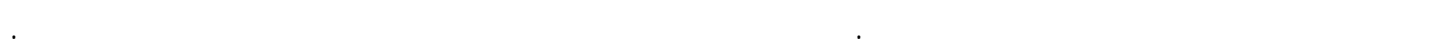

\begin{abstract}
This paper describes a study on electric and thermal stresses induced in bidirectional switches used for control of small power motors present in household appliances, in order to find out the possible weakness of the current solution generally made of a triac and to determine the requirements for new dedicated devices in the $\mathrm{ASD}^{\mathrm{TM}}$ technology. First, a behavioral analysis of these motors must be performed and the interactions between the switch and the load have to be well defined.
\end{abstract}

KEYWORDS: Electric Stress, Switching Components, Induction Motor, Synchronous Motor, Household Appliances.

\section{Introduction}

$\mathbf{N}$ owadays, many of the AC solid-state switches are used to drive different actuators directly supplied on the mains, such as loads which are present in the large and highly competitive household appliances industry. As the features offered to the customers have increased significantly while the price remains almost the same, suppliers have to develop new highly customized cost effective loads for high volume production (Lloyd and Sood, 2000). Therefore, these new loads have led to new driving circuits and thereby new electric stresses in the alternative switches used in these circuits (Galtié et al, 2000).

In this paper, we present the behavioral analysis of different small power motors used in household appliances, i.e. in dishwashers and washing machines as drain pumps, like the singlephase induction motor and the single-phase synchronous motor. These motors are well suited to be driven directly on the mains with a very simple control circuit made of a single triac. Since these motors are 'just-proportioned' for the running condition, a variation of this steady-state condition leads to the variation of the stress involved in the switching device. A complete study of the electrical behavior of these motors has been made regarding the application requirements, such as locked rotor condition or the European $50 \mathrm{~Hz}$ mains shift $\left(220 \mathrm{~V}_{\mathrm{RMS}}\right.$ with a variation of $\left.\pm 10 \%\right)$. 
From this behavioral study, it is possible to design new dedicated power switching devices in the $\mathrm{ASD}^{\mathrm{TM}}$ technology developed by STMicroelectronics in Tours, France, and based on the functional integration concept (Pezzani and Quoirin, 1995), (Quoirin and Pezzani, 1997).

\section{The Single-Phase Induction Motors}

The induction motors are the most widely used in appliances. This kind of motors have poor starting performance and poor efficiency (below 30\%). The power range of these motors is generally less than $100 \mathrm{~W}$. They are often chosen for their reliability and robustness (Lloyd and Sood, 2000).

The different induction motors we worked on are mainly used as drain pumps and are singlephase motors. The stator is made of one or several windings. The rotor may be a short-circuited coil or a squirrel cage. The alternating current passing through the stator creates a revolving magnetic field. Therefore, a current is induced in the rotor. According to the Lenz relation, the rotor tries to annihilate this current involving its self-rotation. However, the rotor's speed is less than the synchronism one. Indeed, the rotor must lag the stator revolving field otherwise the induced current in the rotor is cancelled and there is no motion. The speed variation between the rotor $\left(\Omega_{\mathrm{r}}\right)$ and the stator $\left(\Omega_{\mathrm{s}}\right)$ is called the slip.

$$
g=\frac{\Omega_{s}-\Omega_{r}}{\Omega_{s}}
$$

Since the driving torque $\Gamma$. is always equal to the resistant torque whenever the motor runs, a resistant torque increase leads to the rotor rate decrease and the slip tends towards one.

$$
\Gamma=\frac{P}{\Omega_{r}}
$$

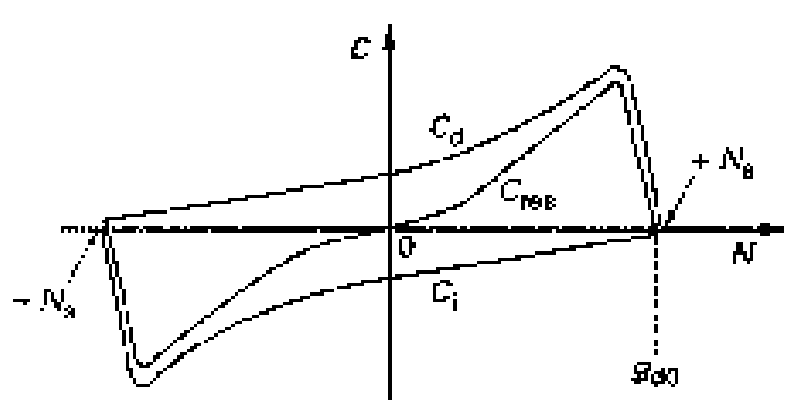

Figure1. Torque-speed characteristics of the single-phase induction motor with: $\mathrm{C}_{\mathrm{d}}$ : Direct torque, $\mathrm{C}_{\mathrm{i}}$ : Inverse torque, $\mathrm{C}_{\mathrm{res}}$ : Resulting torque.

As it has been explained previously, the stator can only generate an alternating field that can be decomposed into two opposite rotating fields (Figure 1). As it can be seen in the Figure, there is no starting torque and the rotor can start in either direction. To manage this issue, a short-circuited secondary winding is added to the motor in order to shade part of the flux from the main pole. This secondary winding is called "Frager's turn". Since the torque characteristic is not symmetrical anymore, the motor is able to start always in the same direction with a poor torque. 


\section{ANALYSIS OF ELECTRIC STRESSES IN AC SWITCHES}

\subsection{Electrical Modeling}

The three-phase model of motor (Figure 2) is valid for one phase only if the motor works in steady state condition with constant speed and torque. The way to obtain all these parameters is well known. This method is well suited for motors with an "empty loaded" slip less than $1 \%$ in order to assume it as zero. Since the single-phase motors tested present a slip in this condition of about 3 to $6 \%$, the calculation leads to an unphysical solution such as negative resistance. Therefore, the model that can be used is a simple RLC type model (Figure 3). The different parameters are determined thanks to the watt-full and the watt-less power measurements. As this kind of motors is "just-proportioned" for the nominal working, saturation effect or iron losses increase lead to different behaviors. Thereby, the model's parameters have to be redefined in each condition:

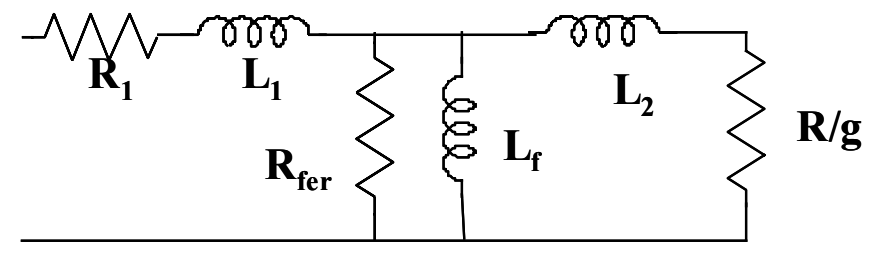

Figure 2. One phase equivalent model for the induction motor with:

$\mathrm{L}_{1}$ : Stator inductance; $\mathrm{L}_{2}$ : Rotor inductance brought back to the stator; $\mathrm{L}_{\mathrm{f}}$ : Leakage inductance; $\mathrm{R}_{\mathrm{f}}$ : Resistance corresponding to Iron loss; R: Rotor resistance brought back to the stator; $\mathrm{R}_{1}$ : Stator resistance, g: Slip.

"empty-loaded", "full-loaded" or locked rotor condition. Moreover, a capacitor is added to the model in order to take into account the parasitic capacitance stemming from the coil turns and the coil layers. For example, for $\mathrm{V}_{\text {mains }}=220 \mathrm{~V}_{\mathrm{RMS}}$ and in locked rotor condition, the model's parameters are the followings: $\mathrm{R}=130 \Omega, \mathrm{L}=0.6 \mathrm{H}$, and $\mathrm{C}=160 \mathrm{pF}$.

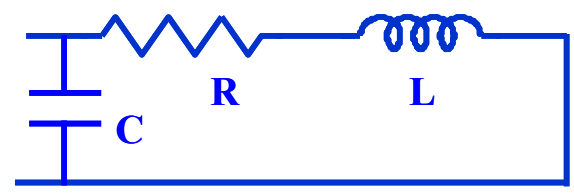

Figure3. Simplified model for the single-phase induction motor.

\subsection{Behavioral Analysis}

In a full loaded condition, the inrush current is increased by $5 \%$ and the steady state current by $10 \%$ in comparison with the empty loaded working condition. The inrush current is 3 to 5 times greater than the steady state current, but its rate of rise is limited by the inductive behavior of the stator (Figure 4). The transient response duration is about $20 \mathrm{~ms}$. The steady state current depends on the motor dimension and its value ranges between 1.5 and $2.5 \mathrm{~A}_{\mathrm{RMS}}$.

At the turn-off, the kind of induction motor we worked on cannot behave like an alternator. However, when is switch turned off, a weak oscillating EMF $(50 \mathrm{~V})$ is generated due to the magnetic remanence (Figure 5).

In locked rotor condition, the overall current shape looks like that of the running condition but the steady state amplitude is always greater. Indeed, the slip is equal to one and the ratio $\mathrm{R} / \mathrm{g}$ is minimum. When the driving switch is turned off, a small voltage without oscillations appears on the motor terminals, due to the magnetic remanence. 


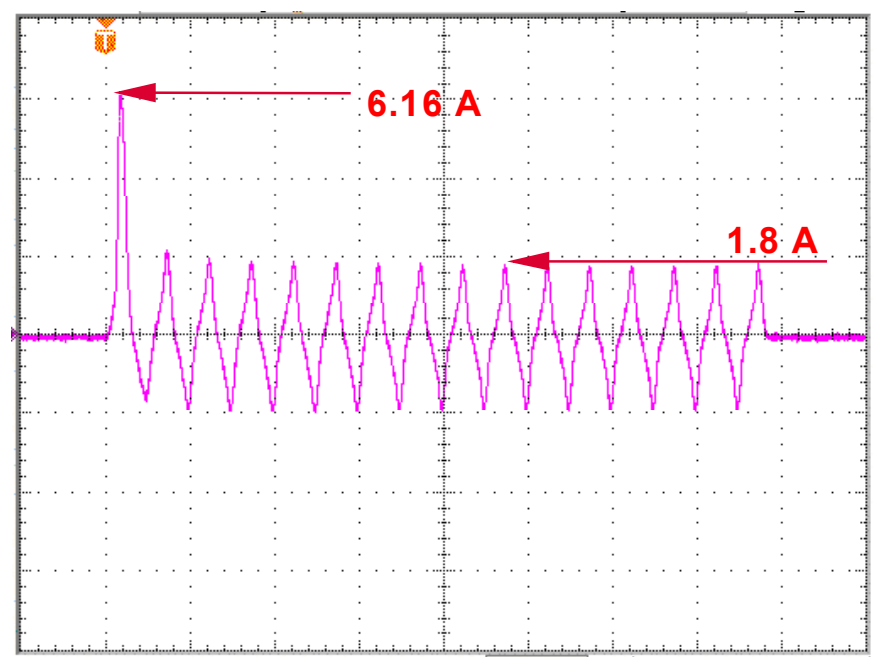

Figure 4. Inrush current and steady state current in the induction motor.

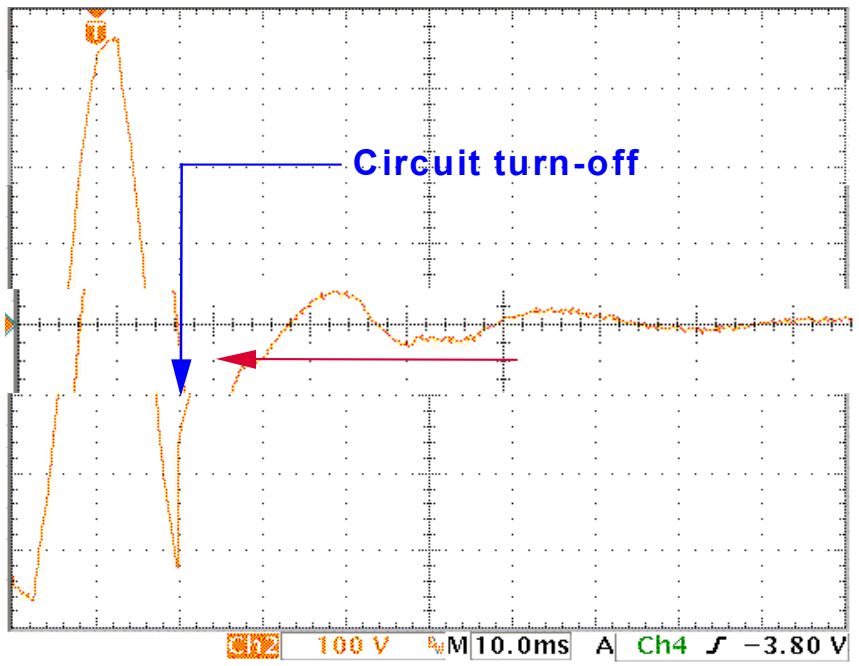

Figure 5. EMF on the motor terminals at the circuit turn-off.

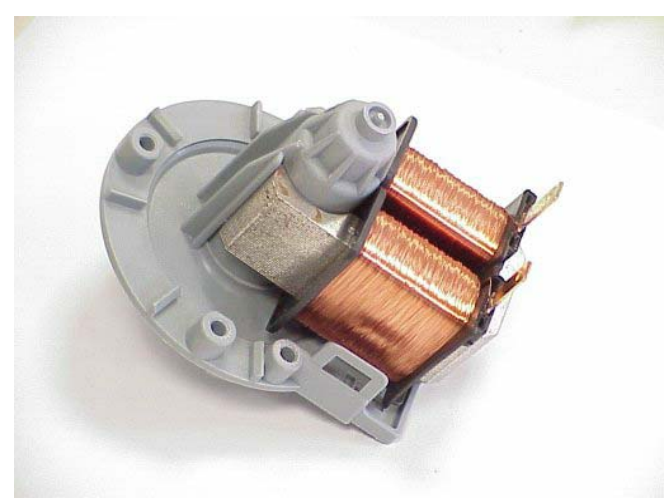

Figure 6. Typical presentation of a single-phase PM synchronous motor.

\section{The Single-Phase Synchronous Motors}

Construction of a single-phase permanent magnet (PM) synchronous motor is simple with the stator being a core of U-shaped laminations with two bobbin wound coils slid over the core to form the stator winding. The rotor is a simple ferrite cylindrical magnet magnetized with two poles 
(Figure 6). The presence of one or several permanent magnets generates a rotor field and the mains generates an AC current in the stator winding, therefore a revolving field. The PM rotor field locks in with the revolving field of the stator so that the motor runs precisely at the synchronous speed of the stator field. The torque-speed characteristic of a single-phase PM synchronous motor is shown on Figure 7 where the curve is a straight line parallel to the torque axis. Intersection of this line with the speed axis defines the synchronism speed $\Omega_{\mathrm{S}}$. With this characteristic, only an external action on the driving shaft will change the torque's value and such action induces changing of the $\mathrm{C}_{\mathrm{R}}(\Omega)$ characteristics but the speed remains the same.

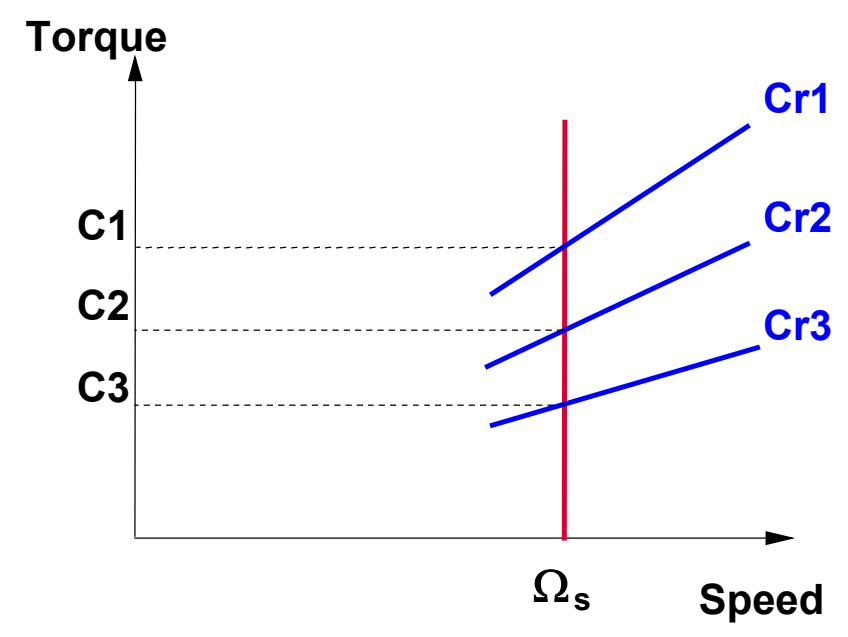

Figure 7. Torque-speed characteristic of a single-phase PM synchronous motor.

This kind of motor has an oscillatory starting characteristic and will start in either direction. To obtain a required direction of rotation and a minimum torque when the motor is starting, it is necessary to give an irregular shape to the air gap. These motors have found a niche market in drain pumps for washing machines and dishwashers with power ratings of around $30 \mathrm{~W}$. They are replacing the single-phase induction motors because of their better efficiency close to twice that of the single-phase induction motors (about 50\%) and their relatively low cost (Lloyd and Sood, 2000). A U-shaped, 2-pole motor is a recent variation of PM synchronous motors.

\subsection{Electrical Modeling}

When the motor is running, the rotor field induces a variable flux in the stator winding. This variation generates a sinusoidal-shaped electromotive force (EMF). An equivalent circuit of the motor is shown Figure 8, where a capacitor is added in order to take into account the parasitic capacitance of the stator winding. For $\mathrm{V}_{\text {mains }}=264 \mathrm{~V}_{\mathrm{RMS}}$, the typical values obtained are $\mathrm{R}=180$ $\Omega ; \mathrm{L}=1.4 \mathrm{H}, \mathrm{C}=100 \mathrm{pF}, \mathrm{E}=218 \mathrm{~V}_{\mathrm{RMS}}$.

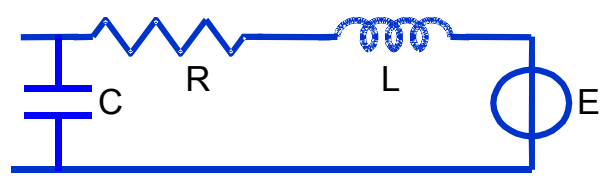

Figure 8. Equivalent circuit of synchronous motor running.

\subsection{Behavioral Analysis}

In locked rotor condition, the steady-state current is typically $0.7 \mathrm{~A}_{\mathrm{RMS}}$, i.e. 2.5 times greater than the running value. The most important measured $(\mathrm{dV} / \mathrm{dt})_{\mathrm{C}}$ (locked rotor) is $11.9 \mathrm{~V} / \mu \mathrm{s}$ for $(\mathrm{di} / \mathrm{dt})_{\mathrm{C}}$ equal to $0.16 \mathrm{~A} / \mathrm{ms}$ at $25^{\circ} \mathrm{C}$, with switching devices specified for $1 \mathrm{~V} / \mu$ s and $0.35 \mathrm{~A} / \mathrm{ms}$ at $100^{\circ} \mathrm{C}$. 


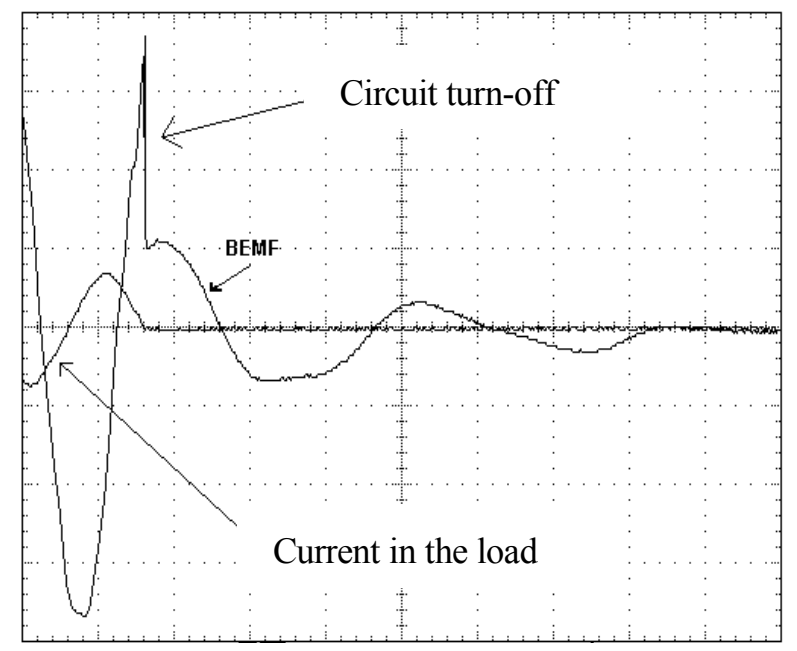

Figure 9. Presence of an oscillatory voltage at terminals of synchronous motor when the switch turns off.

When the control device is switching off, the EMF generated by the synchronous motor working as an alternator is not negligible since it can be up to 100 volts (Figure 9). When the motor is in a deceleration phase, the voltage does not present a constant period or amplitude and modifies the applied voltage to the device during the turn-off. The EMF generally decreases the amplitude of the mains applied at commutation and thus decreases the rate of increase of this voltage $:(\mathrm{dV} / \mathrm{dt})_{\mathrm{C}}$.

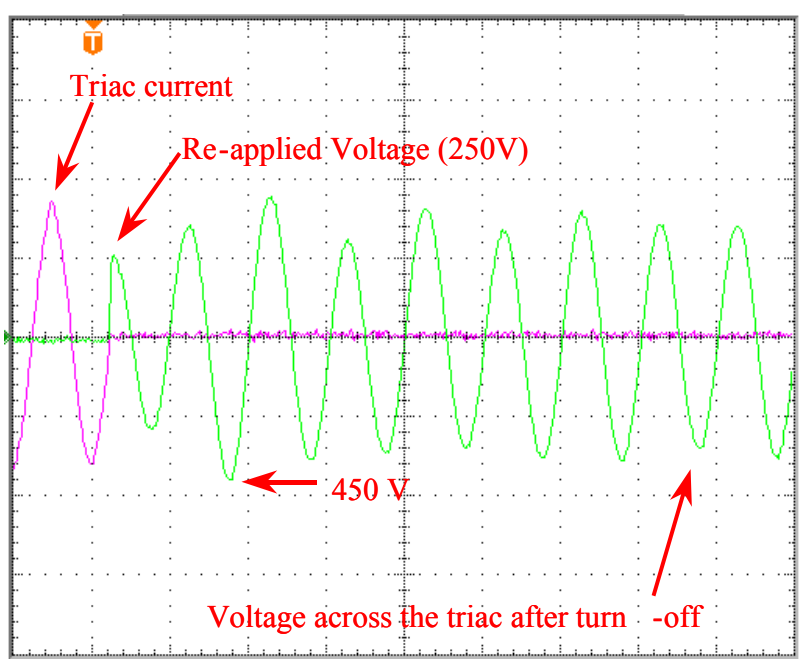

Figure 10. Applied voltage on the triac after the PM synchronous motor commutation.

Since the EMF modifies the voltage across the device, the Figure 10 shows that the voltage can be higher than the mains amplitude and therefore the component off-state capability must be suitable. However, in this instance, the voltage reaches only $450 \mathrm{~V}$ that is less than the off-state voltage withstood by most of the triac $\left(\mathrm{V}_{\mathrm{DRM}} / \mathrm{V}_{\mathrm{RRM}}=600 \mathrm{~V}\right)$.

\section{Switch-Load Interaction}

The electric behavior of the two foregoing motors induces electric and thermal stresses on the control switch and it is very important to know them either for the choice of the switch or for the design of a new component in the $\mathrm{ASD}^{\mathrm{TM}}$ technology. In this section, we present the stresses 
induced by the load on the switch at the turn-on, in the on-state, at the turn-off and in the offstate.

\subsection{Switch Turn-on}

Each kind of motors presents a parasitic capacitance due to the stator winding. So, when the device turns on while $\mathrm{V}_{\text {mains }}=264 \mathrm{~V}_{\mathrm{RMS}}$, the capacitive current rate of rise is about $(\mathrm{di} / \mathrm{dt}) \approx 15 \mathrm{~A} / \mu$ s with a weak amplitude $(0.8 \mathrm{~A})$. However this measured value of $(\mathrm{di} / \mathrm{dt})$ is higher than the repetitive critical rate of rise of on-state current given by conventional triacs datasheets, i.e. $10 \mathrm{~A} / \mu \mathrm{s}$. It would be better to fire the triac at the zero voltage crossing of the mains.
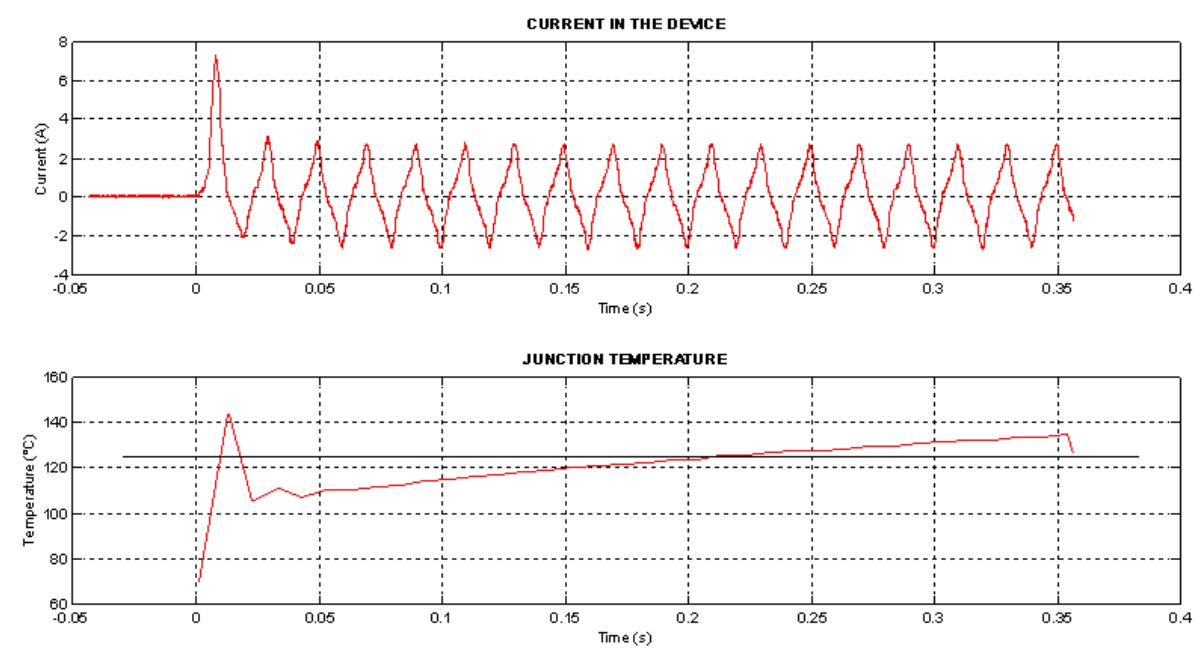

Figure 11. Thermal simulation of a triac junction temperature during the locked rotor condition.

\subsection{Switch on-state}

The control switch on-state induces an inrush current from 2 to 5 times greater than the steady state current. The worst case occurs when each kind of motors is in locked rotor condition. In this case, the steady state current is noticeably increased and the device temperature as well. Thermal simulation has been performed to determine if the switching device is able to withstand a temperature increase without causing damage or affecting the reliability. Figure 11 shows the thermal simulation of a triac junction temperature $(\mathrm{Z} 01 \mathrm{xx}$, in TO92 package, STMicroelectronics) during the locked rotor condition of an induction motor.

The initial temperature has been chosen equal to $60^{\circ} \mathrm{C}$, i.e. the ambient temperature inside a washer. We can observe that the temperature increases over $125^{\circ} \mathrm{C}$, which is the maximum temperature allowed in the device. This device is not suitable to control this kind of motor.

\subsection{Switch turn-off}

The current cancellation in the device involves the circuit turn-off. The motors being inductive loads, the device turn-off is not obtained at the zero volt of the mains. Consequently, the rate of rise of the voltage $(\mathrm{dV} / \mathrm{dt})_{\mathrm{c}}$ is greater than the one obtained when the switching occurs at the zero voltage. This $(\mathrm{dV} / \mathrm{dt})_{\mathrm{c}}$ value can produce an unwanted firing especially if the current rate of decrease is high. So, the commutation capability is a function of $(\mathrm{di} / \mathrm{dt})_{\mathrm{c}}$ and $(\mathrm{dV} / \mathrm{dt})_{\mathrm{c}}$. The most important measured $(\mathrm{dV} / \mathrm{dt})_{\mathrm{c}}$ is $18 \mathrm{~V} / \mu \mathrm{s}$ for a $(\mathrm{di} / \mathrm{dt})_{\mathrm{c}}$ equal to $0.6 \mathrm{~A} / \mathrm{ms}$. The device used is a triac specified for $\mathrm{I}_{\mathrm{TRMS}}=4 \mathrm{~A},(\mathrm{di} / \mathrm{dt})_{\mathrm{c}}=1.8 \mathrm{~A} / \mathrm{ms} @(\mathrm{dV} / \mathrm{dt})_{\mathrm{c}}=20 \mathrm{~V} / \mu \mathrm{s}$ at $\mathrm{T}_{\mathrm{j}}=125^{\circ} \mathrm{C}$. This device is well dimensioned regarding the commutation stress but it is over dimensioned regarding the current capability ( $4 \mathrm{~A}_{\mathrm{RMS}}$ instead of $1.5 \mathrm{~A}_{\mathrm{RMS}}$ needed in locked rotor condition). 


\subsection{Switch off-state}

In off-state condition, the control switch must withstand a forward or reverse voltage $\left(\mathrm{V}_{\mathrm{DRM}} / \mathrm{V}_{\mathrm{RRM}}\right)$ without causing an unwanted firing. Indeed, the triac must not work in breakdown condition in order to avoid any instant failure or to reduce its reliability. Figure 10 shows that the voltage across the triac after the turn-off reaches $450 \mathrm{~V}$. Consequently, a well suited device must be chosen with at least a $\mathrm{V}_{\mathrm{DRM}} / \mathrm{V}_{\mathrm{RRM}}=600 \mathrm{~V}$.

\section{Conclusion}

The behavior analysis of different small power motors used in household appliances (diswashers and washing machines) allows a better knowledge of their empty loaded and full loaded characteristics. The single-phase induction motor and the single-phase permanent magnet synchronous motor are usually used as drain pumps. Suppliers have to develop new customized loads characterized by their reliability and robustness. In these loads, current and voltage observation for different working conditions (full loaded, empty loaded, locked rotor) shows electric and thermal stresses induced on the control switch:

- amplitude and duration of inrush current.

- amplitude of steady state current in the locked rotor condition.

- temperature increasing in the component in the steady state condition and locked rotor,

- EMF added to the mains when the device turns off.

- $(\mathrm{dV} / \mathrm{dt})_{\mathrm{c}}$ and $(\mathrm{di} / \mathrm{dt})_{\mathrm{c}}$ when the device turns off.

All these parameters must be taken into account to choose a usual component or to design a new-dedicated power switching device in the $\mathrm{ASD}^{\mathrm{TM}}$ technology.

\section{References}

GALTIE, F., RAINGEAUD, Y., GONTHIER, L. and BAILLOU, J. 2000. Analyse de systèmes conduisant à la conception de composants dédiés dans la filière $\mathrm{ASD}^{\mathrm{TM}}$ : Application à divers actionneurs de petite puissance. Proceedings of EPF 2000, Lille, France, december 2000.

LLOYD, J.D. and SOOD, P.K. 2000. Motor technology for major household appliances. Confortec International Appliance Tech. Forum, Paris, France, 2000.

PEZZANI, R. and QUOIRIN, J.B. 1995. Functional integration of power devices : a new approach. Proceeding of EPE'95, Sevilla, Spain, 2.219-2.223.

QUOIRIN, J.B. and PEZZANI, R. 1997. Intégration monolithique, état de l'art et tendance future. Forum européen des semiconducteurs de puissance, Club CRIN - SEE, Paris, France, 9-14.

Received 3 June 2001

Accepted 18 January 2002 